\title{
Muslim Minorities in the West
}

\author{
By Syed Z. Abedin and Ziauddin Sardar, eds. London: Grey Seal \\ (Publications) Limited, 1995, 212 pp.
}

In this superb compilation of essays, fourteen scholars provide a timely assessment of the expanding Muslim communities in ten western countries, carefully describing their growth and development, sometimes in minute historical detail, as they are increasingly scrutinized under the global spotlight for a variety of complex reasons. Produced as a serious work of research, this volume represents one of the first attempts to examine systematically the status and nature of Muslim collective life in the western diaspora as seen from the theoretical perspective of the majority-minority relationship. It developed out of a conference convened to consider the condition of the Islamic minorities worldwide. After the conference, selected papers were transformed into chapters written specifically for inclusion in this book.

Through fourteen rich and original articles, this book explores a plethora of problems confronting Muslims, both the recent immigrant arrivals in Europe, Australia, and North America as well as the indigenous followers of Islam in the Balkans, living within communal collectivities of the Western world. It considers "how Muslim minorities fulfill their religious rites and obligations, engage in social and community life and educate their young." It examines "the sacrifices Muslims have to make and the price they have to pay to maintain or to acquire a Muslim identity." With two essays each on Australia, Canada, and the United States, and Britain, the English-speaking world, gets the most attention. But the more obscure cases of Bosnia and Bulgaria, both the terra incognita of the Islamic world until the recent tragedy, are analyzed thoroughly by their native sons, Smail Balic and Kemal Karpat. Despite a diversity of academic orientation, the essays are all highly stimulating, and the quality of the contributions are all equally superior.

The overarching dilemma, identified by the authors as the culprit responsible for the Muslims' difficulties, is the demonization of Islam and the Islamic people in the western worldview. As a powerful psychological force on western thinking, this mindset has brought about the victimization of Muslims and has led to their wholesale discrimination, indeed, to their rejection as the undesirable "other." The first two chapters of the book, directly relevant to this concern, delve into the agony of the Muslims of Bosnia; despite their ethnic and racial compatibility with the Slavic majority notwithstanding, they have undergone one of the most gruesome incidents of calculated mass murder and brutality in recent European history. In spite of Bosnia's "open-minded, liberal and tolerant" (p. 23) nature, it has not been spared "a ruthless genocide" (p. 24), perhaps because Islam rejects the underlying racist premise of the nation-state and is therefore seen as a subversive force. Commensurately, history seems to be repeating itself in Europe. Almost five hundred years after the obliteration of Islam from Spain, Khalid Duran points out that Bosnia, "truly a cosmopolitan society" (p. 30), is being turned into another Andalusia. 
The chapter on Bulgaria documents yet another episode in the tragic plight of Balkan Muslims. The Bulgarian treatment of ethnic Turks, their forced Bulgarianization, is once again an exercise in racial purification of a nation-state so as to make the state compatible with the nation. Muslim Turks were no doubt seen as the harbingers of pluralism and multiculturalism, a dangerous idea in the insular and nationalist European mind.

The selections on Britain, Germany, the Netherlands, Australia, Spain, and Portugal analyze immigrant Muslim communities whose rapid growth constitutes a serious challenge both to the host societies and the newcomers. Despite professions of democracy and pluralism in many of these countries, Muslims are viewed with suspicion, perceived through racist lenses as the classical "other," darkly threatening, and unassimilateable. In the most democratic of nations, Britain, Muslims are portrayed "as a threat to the culture and values of British society" (p. 48), which is an insidious, widely believed stereotypical view. Prejudicial attitudes of this type are pervasive, and in Britain, it has led to the denial of permission to Muslims to establish Islamic schools.

In the Netherlands, however, while there are "no obstacles for Islam to establish itself" (p. 91), it is the Muslim community that, because of its disorganization and fragmentation, has been unable to take advantage of the opportunities offered. The lack of educational sophistication and the absence of rational skills for social interaction are among the most fundamental shortcomings common to Muslims in the diaspora. In fact, Riaz Hassan's finding on Australia that "Muslims have much lower schooling levels than the nonMuslim majority" (p. 126) applies to Muslims virtually everywhere, including those in the Islamic heartland. The world of Islam, furthermore, constitutes the core of underdevelopment, with the result that Muslims' difficulties in adjustment and acculturation are compounded by their largely rural origin, having grown up in traditional villages and migrated to complex, highly urbanized, industrial societies.

The book points out that Muslims in the United States and Canada, having been admitted under selective immigration policies, "are among the most highly educated" (p. 138) people in North America. Consequently, they possess a higher level of skills, and substantial numbers are employed in the professions and are relatively integrated into the society's mainstream. Despite their ostensible success, Daood Hassan Hamdani finds that "Muslims experience a considerably higher unemployment rate than Christians and Jews" (p. 157), and so while qualifications do matter, there is evidently "a certain degree of discrimination" (p. 157) operating in the labor market.

The essays in the collection are replete with references to the preservation of Islamic identity as the paramount concern of Muslims, as they are embraced ever so tightly by the aggrandizing western culture. The calculated response to this challenge has made "education and Muslim schools such passionate issues with Muslim communities throughout the West" (p. 13). The value of education as a powerful tool for minority survival is presented most forcefully by Theodore Pulcini in his thoroughly researched and highly analytical essay, "Values Conflict Among U.S. Muslim Youth." He argues that Muslims in the West should underscore their particularity and emphasize "a strong assertive in-group identification" while insisting on "social recognition of its positively valued distinctiveness" (p. 196). These positive attributes, however, could only be cultivated through the development of the intellect and the acquisition of knowledge. 
The institution of schooling for the transmission of values, therefore, becomes an imperative for the community.

Indisputably, Muslims "have come to believe that the Islamic identity of their children, as well as their rich cultural and religious heritage can only be preserved by establishing their own schools" (p. 13). Moreover, education has also come to be viewed as the logical instrument for social mobility and for integration into the mainstream of the majority society. A secure Muslim minority, if intellectually proficient, can also overcome the forces of racism and discrimination and, at the same time, make contributions to the pluralism of its adopted homelands. Knowledge and intellectual skills are seen as the means for empowerment both in the economic marketplace and in the political arena.

While this work is a welcome addition to an incipient empirically grounded social scientific literature on Muslims, it is particularly noteworthy for its inclusion of people who are being written about and whose lives are being addressed. The arrangement of the book, however, seems a little awkward. For example, there seems to be no particular order discernible, especially when the selection on Britain is placed between Bosnia and Bulgaria. The reader is left wondering whether it is alphabetical; if so, then what is Australia doing right in the middle? Perhaps some other form of arrangement could have provided a logical coherence and continuity with an ease of transition from one chapter to another. One very important country, France, has been left out; its inclusion could have substantially strengthened the collection. The same point can be made about Belgium, which was one of the first European countries to extend official recognition to Islam within its borders.

Nevertheless, this work represents sound scholarship that analyzes painstakingly gathered and carefully pieced together information on Muslim minorities that is not easily accessible to the nonspecialist outsider. The editors deserve credit for its production, the first book devoted exclusively to the examination of Muslim life in the West. Despite its essentially social science approach, it is mercifully free of scientific jargon and is likely to appeal to the general reader. It deserves to be read widely, both by Islamic activists and by students of social science phenomena.

Ghulam M. Haniff Deparment of lnterdisciplinary Studies St. Cloud State Univensity St. Cloud, Minnesota 